Article

\title{
Kinetic Analysis of 4-Nitrophenol Reduction by "Water-Soluble" Palladium Nanoparticles
}

\author{
Anas Iben Ayad ${ }^{1} \mathbb{D}$, Denis Luart ${ }^{2}$, Aissa Ould Dris ${ }^{1}$ and Erwann Guénin ${ }^{1, * \mathbb{C}}$ \\ 1 TIMR (Integrated Transformations of Renewable Matter), ESCOM, Centre de Recherche Royallieu, \\ Université de Technologie de Compiègne, CS 60319, CEDEX, 60203 Compiègne, France; \\ anas.iben-ayad@utc.fr (A.I.A.); aissa.ould-dris@utc.fr (A.O.D.) \\ 2 Laboratoire TIMR, EA4297, ESCOM-École Supérieure de Chimie Organique et Minérale, 1 Allée du Réseau \\ Buckmaster, 60200 Compiègne, France; d.luart@escom.fr \\ * Correspondence: erwann.guenin@utc.fr; Tel.: +33-(0)7-6822-0981
}

Received: 11 May 2020; Accepted: 12 June 2020; Published: 15 June 2020

check for updates

\begin{abstract}
The most important model catalytic reaction to test the catalytic activity of metal nanoparticles is the reduction of 4-nitrophenol to 4-aminophenol by sodium borohydride as it can be precisely monitored by UV-vis spectroscopy with high accuracy. This work presents the catalytic reduction of 4-nitrophenol (4-Nip) to 4-aminophenol (4-Amp) in the presence of Pd nanoparticles and sodium borohydride as reductants in water. We first evaluate the kinetics using classical pseudo first-order kinetics. We report the effects of different initial 4-Nip and $\mathrm{NaBH}_{4}$ concentrations, reaction temperatures, and mass of $\mathrm{Pd}$ nanoparticles used for catalytic reduction. The thermodynamic parameters (activation energy, enthalpy, and entropy) were also determined. Results show that the kinetics are highly dependent on the reactant ratio and that pseudo first-order simplification is not always fit to describe the kinetics of the reaction. Assuming that all steps of this reaction proceed only on the surface of Pd nanoparticles, we applied a Langmuir-Hinshelwood model to describe the kinetics of the reaction. Experimental data of the decay rate of 4-nitrophenol were successfully fitted to the theoretical values obtained from the Langmuir-Hinshelwood model and all thermodynamic parameters, the true rate constant $k$, as well as the adsorption constants of 4-Nip, and $\mathrm{BH}_{4}^{-}\left(K_{4-\mathrm{Nip}}\right.$ and $\left.\mathrm{K}_{\mathrm{BH} 4-}\right)$ were determined for each temperature.
\end{abstract}

Keywords: Palladium nanoparticles; 4-nitrophenol reduction; Langmuir-Hinshelwood Model; kinetics; thermodynamics

\section{Introduction}

The world of nanoscience involving metallic nanoparticles (mNPs) has been the subject of numerous scientific and technological research studies during recent years. Thus far, the art of synthesizing mNPs and nanoalloys in a large range with full control of different shapes and sizes has resulted in widespread applications in engineering, electronics, and catalysis [1]. mNPs such as palladium, platinum, and gold have already shown their potential in catalysis of several specific reactions, such as hydrogenation, water splitting, and cross-coupling reactions [2]. For example, bulk inert metals such as gold may become active in catalysis when divided into nanometer dimensions $[3,4]$. The redox potential value of metallic nanoparticles becomes progressively negative depending on their Fermi level that is related to their size [5-7].

4-Nitrophenol is a significant side product obtained from pharmaceutical industries, synthetic dyes, herbicides, and pesticides. Additionally, it is known as a hazardous product, and its removal from the environment is an important goal because of the negative effect on human and animal blood as well as several organs [8-10]. Therefore, its catalytic reduction by several mNPs has been a continuous 
subject of research for several years. The reduction of 4-nitrophenol by sodium borohydride is a model reaction to evaluate the catalytic activity of $\mathrm{mNPs}$ and to study the reaction kinetics. The main reasons for the use of this reaction as a model are that the reaction is well-controlled in the presence of the mNPs without by-product formation, and that the kinetics analysis of the reaction rate as a function of temperature is easily monitored by UV-vis spectroscopy. The presence of isosbestic points in the UV-vis absorption spectra at different times provides clear proof that 4-nitrophenol is completely reduced to 4-aminophenol with no side products generated. In addition, this reaction proceeds under mild conditions (at room temperature in water as a solvent). Thus, this model reaction has become a benchmark reaction of mNPs (see Table S1 in the Electronic Supplementary Information of the review of P. Hervés et al. [11]); the fundamental (kinetics) catalytic model reaction for mNPs has been described by several authors $[7,12,13]$. Almost all authors consider that the catalytic reduction of 4-nitrophenol (4-Nip) takes place on the surface of the mNPs [8,14], of which a prerequisite is that all reactants, 4-Nip, and borohydride ion must be adsorbed on the surface of mNPs to react. The apparent rate constant $k_{a p p}$ is determined in terms of pseudo first-order kinetics.

In this work, we propose to study the catalytic reduction of 4-nitrophenol (4-Nip) to 4-aminophenol (4-Amp) in the presence of Pd NPs and sodium borohydride as a reductant in water and to study the kinetics of the reaction. These Pd NPs are obtained in a simple and eco-friendly manner and have already shown high efficiency for several organic reactions in aqueous media [15]. Therefore, understanding their kinetics in a well-defined model such as 4-Nip reduction is of interest.

\section{Materials and Methods}

\subsection{Chemicals}

$\mathrm{Na}_{2} \mathrm{PdCl}_{4}$, sodium ascorbate, and $\mathrm{NaBH}_{4}$ were purchased from Sigma-Aldrich (Saint-Quentin Fallavier, France), while 4-nitrophenol was acquired from Acros Organics - Fisher Scientific (Illkirch, France). All materials and solvents were used as received without further purification. Nanopure water $\left(18 \mathrm{M} \Omega \mathrm{cm}^{-1}\right)$, obtained from a Millipore Gradiant Elix-3A10 system (Millipore SAS, Molsheim, France), was used for all experiments. Synthesis and characterization of the Pd NPs as well as their bisphosphonic acid ligand were performed using the protocols described in our previous work [15].

\subsection{Dynamic Light Scattering (DLS) Analysis}

The average hydrodynamic radius of $\mathrm{Pd}$ nanoparticles was observed in water at $\mathrm{pH}=7$ by a DLS (Dynamic Light Scattering) Litesizer 500 Anton Paar particle size analyzer (Anton Paar France, Courtabeouf, France). The measurements were performed in quartz cuvettes at a temperature 293.15 K, laser wavelength $658 \mathrm{~nm}$ (single-frequency laser diode), detection angle $175^{\circ}$, medium viscosity 0.8903 $\mathrm{mPa} \cdot \mathrm{s}$, and medium refractive index 1.3303 .

\subsection{Spectrophotometer (UV-vis) Analysis}

The catalytic reduction of 4-nitrophenol was monitored by a Perkin-Elmer Lambda-2 UV-vis Spectrophotometer (PerkinElmer France, Villebon-sur-Yvette, France) employing a $1 \mathrm{~cm}$ path length quartz cuvette (Hellma). The experimental error of the wavelength values was estimated to be $1 \mathrm{~nm}$.

\subsection{Catalytic Reduction of 4-Nitrophenol}

The catalytic reduction of 4-nitrophenol (4-Nip) to 4-aminophenol (4-Amp) in the presence of NPs and sodium borohydride as a reductant was previously described in the literature [16-18]. Briefly, the UV absorption measurements were performed in a $3 \mathrm{~mL}$ quartz cell. The solutions of 4-Nip and $\mathrm{NaBH}_{4}$ were freshly prepared before each measurement, without purging with $\mathrm{N}_{2}$ [16]. In a typical experiment, $30 \mu \mathrm{L}$ of 4 -Nip $\left(7.5 \times 10^{-3} \mathrm{M}\right)$ solution was added to the reaction medium $(2.8 \mathrm{~mL}$ of water) with $200 \mu \mathrm{L}$ of sodium borohydride solution $(0.169 \mathrm{M})$; the ratio of sodium borohydride to 4-Nip concentration in the medium was equal to 150. Under these conditions, all 4-Nip was transformed into 
4-nitrophenolate, which was detected at $\lambda=400 \mathrm{~nm}$. Then, $20 \mu \mathrm{L}$ of NP Pd solution $\left(2.8 \times 10^{-5} \mathrm{M}\right)$ was added to the solution. Immediately after the addition of Pd NPs, time-dependent absorption spectra were recorded at $6 \mathrm{~s}$ intervals for different temperatures.

\section{Kinetics Analysis}

The kinetic data were examined first in terms of pseudo first-order kinetics and then fitted to a Langmuir-Hinshelwood model. There are two types of catalytic mechanisms of 4-Nip reduction. The first one is surface-mediated hydrogen transfer, described by several authors and especially the Ballauff group [8,12,13,16,19], and the second one is surface-mediated electron transfer [20,21].

We assume that both catalytic mechanisms are involved in this reaction. Both reactants, 4-Nip and borohydride ions, must absorb onto the surface of mNPs before the reduction of 4-Nip. The reaction goes through two stages: the first stage includes two steps, the equilibrated adsorption of borohydride ions and production of the hydrogen radical by electron transfer $[22,23]$.

The second stage includes three steps, the equilibrated adsorption of 4-Nitrophenolate, the addition of hydrogen species to the adsorbed molecule to form the 4-aminophenol via the formation of the 4-hydroxylaminophenol intermediate [16,24], and the removal of two water molecules from the nitro group, and finally the detachment of the 4-aminophenol molecule from the nanoparticle surface to provide place for another catalytic cycle. Figure 1 displays the essential process of 4-Nip reduction on the surface of Pd nanoparticles based on the Langmuir-Hinshelwood mechanism.

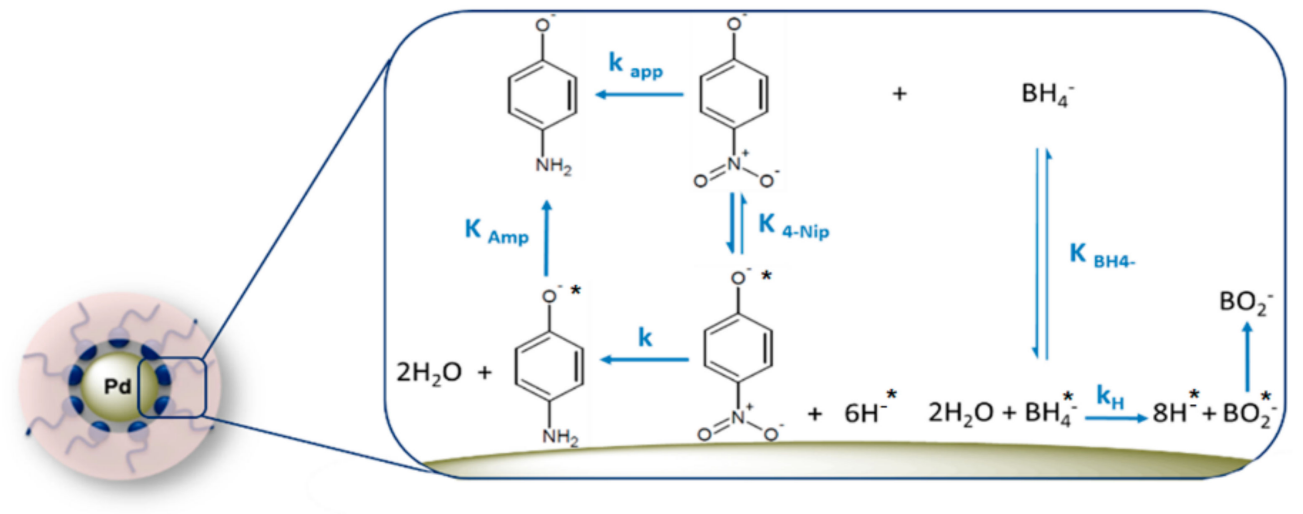

Figure 1. Schematic representation of the Langmuir-Hinshelwood mechanism of 4-Nip reduction on the surface of Pd nanoparticles.

The adsorption of 4-Nip on the surface of the Pd NPs is reversible and is modeled by a Langmuir isotherm [25]. Previous kinetic studies indicated that the reduction of the 4-Nitrophenol molecule adsorbed on the surface, including the surface hydrogen species, is the rate-determining step [13]. Some authors reported that the interaction of borohydride ions with metallic surfaces is a complex mechanism that constitutes several stages [26,27]. Moreover, the production of a surface-hydrogen species by the adsorbed borohydride ion and the final detachment of 4-aminophenol molecule are fast and irreversible; for that reason, these steps do not enter into the Langmuir-Hinshelwood equations [12]. The Langmuir-Hinshelwood equation can be defined as follows:

$$
\frac{d[4-N i p]}{d t}=-k S \theta_{4-N i p} \cdot \theta_{B H_{4}^{-}}=-k_{a p p} \cdot[4-N i p]
$$

where $k$ is the rate constant, $S$ is the total surface of all Pd nanoparticles, accurately proportional to the apparent kinetic constant $k_{a p p}$, and $\theta_{N i p}$ and $\theta_{B H 4}$ indicate the surface coverage values on the surface of 4-Nip and $\mathrm{BH}_{4}{ }^{-}$, which can be expressed by a Langmuir-Freundlich isotherm: 


$$
\begin{aligned}
\theta_{4-N i p} & =\frac{\left(K_{4-N i p} \cdot[4-N i p]\right)^{n}}{\left(1+\left(K_{4-N i p} \cdot[4-N i p]\right)^{n}+\left(K_{B H_{4}^{-}} \cdot\left[B H_{4}^{-}\right]\right)^{m}\right.} \\
\theta_{B H_{4}^{-}} & =\frac{\left(K_{B H_{4}^{-}} \cdot\left[B_{4}^{-}\right]\right)^{m}}{\left(1+\left(K_{4-N i p} \cdot[4-N i p]\right)^{n}+\left(K_{B H_{4}^{-}} \cdot\left[B_{4}^{-}\right]\right)^{m}\right.}
\end{aligned}
$$

where $\mathrm{K}_{4-\mathrm{Nip}}, \mathrm{K}_{\mathrm{BH}} 4^{-}$, [4-Nip], and $\left[\mathrm{BH}_{4}^{-}\right]$are the adsorption constants and the concentrations of 4-Nip and $\mathrm{BH}_{4}{ }^{-}$, respectively. The exponent $\mathrm{n}$ and $\mathrm{m}$ are related to the adsorption and desorption equilibrium of 4-Nip and $\mathrm{BH}_{4}{ }^{-}$molecules, respectively, and they indicate the heterogeneity of the sorbent. The heterogeneity parameters $n$ and $m$ are both equal to 1 according to the classical Langmuir isotherm model [28].

This basic model considers that the surface of the metal catalyst is homogeneous in terms of adsorption energy, which means that the adsorption energy is the same for all sites. Thus, the maximal adsorption capacity is full monolayer coverage, without interaction between adsorbed species. The model of the Langmuir isotherm equation can be defined as follows [28]:

$$
q_{e}=q_{m} \cdot \frac{\left(K_{L} \cdot C_{e}\right)}{1+\left(K_{L} \cdot C_{e}\right)}
$$

where $q_{e}$ is the amount of adsorbate (4-Nip) adsorbed on metal nanoparticles, $q_{m}$ is the maximum saturation load, i.e., the mass of 4-Nip required per gram of metal nanoparticles to form a complete monolayer on the surface, $K_{L}$ is the Langmuir affinity constant related to the equilibrium constant or binding energy, $K_{L} \alpha e^{-\Delta H / R T}$, and $C e$ is the equilibrium concentration of 4-Nip in solution. The past finding of an exponent $n=1$ by some authors for adsorption of 4-nitrophenol and 4-aminophenol may therefore point to the identical outcome [25,29].

Hence, Equation (1) can be rearranged and rewritten as:

$$
\frac{d[4-N i p]}{d t}=\frac{-k \cdot S \cdot K_{4-N i p} \cdot[4-N i p] \cdot K_{B H_{4}^{-}} \cdot\left[B H_{4}^{-}\right]}{\left(1+K_{4-N i p} \cdot[4-N i p]+K_{B H_{4}^{-}} \cdot\left[B H_{4}^{-}\right]\right)^{2}}
$$

Thus, $k_{\text {app }}$ can follow as:

$$
k_{\text {app }}=\frac{k \cdot S \cdot K_{4-N i p} \cdot K_{B H_{4}^{-}} \cdot\left[B H_{4}^{-}\right]}{\left(1+K_{4-N i p} \cdot[4-N i p]+K_{B H_{4}^{-}} \cdot\left[B H_{4}^{-}\right]\right)^{2}}
$$

The true rate constant $k$ is linked to the reaction of the adsorbed species $K_{4-N i p}$ and $K_{B H 4}$ [8]; these constants can be obtained from a fit of the temporal decay of the concentration of 4-Nip to the series of experimental data (see the procedure in the Supporting Information).

In order to obtain the adsorption constants $K_{4-N i p}$ and $K_{B H 4^{-}}$as a function of temperature, the enthalpies and entropy for the adsorption of 4-Nip and $\mathrm{BH}_{4}{ }^{-}$can be obtained from the application of Van't Hoff's equation and by combining the Gibbs free energy equation, respectively.

Van't Hoff's equation:

$$
\frac{d \ln K}{d(1 / T)}=-\frac{\Delta H}{R}
$$

Combining the Gibbs free energy equation:

$$
\ln K=-\frac{\Delta G}{R T}=-\frac{\Delta H}{R T}+\frac{\Delta S}{R}
$$




\section{Results and Discussion}

\subsection{Catalytic Reduction of 4-Nitrophenol Using Pd NPs}

Pd NPs have been shown to be excellent catalysts for different reactions performed in aqueous media, such as carbon-carbon cross-coupling, hydrogenation of alkenes, and oxidation of primary alcohols as shown in our previous work [15]. We used benzyl bisphosphonic acid as a ligand for the nanoparticles (see Figure 2). The median diameter size of the Pd nanoparticles obtained from the TEM micrographs was $6 \mathrm{~nm}$. The specific surface area $(S)$ was calculated based on the median radius [8] and was used in the determination of the kinetic data.

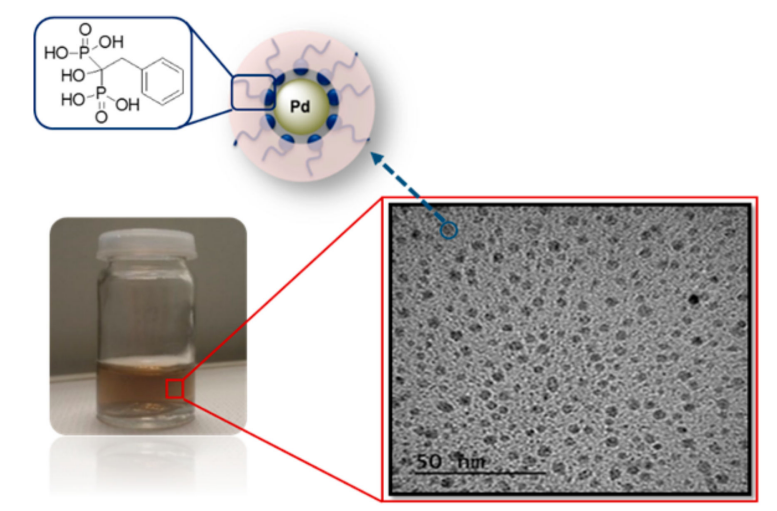

Figure 2. Structure of the Pd NPs used in the kinetic studies. Lower panel, right side: TEM micrograph of Pd-NPs solution (average diameter, $6 \mathrm{~nm}$ ). The upper panel left side: Scheme of the Pd NPs consisting of spherical Pd with benzyl bisphosphonic acid as a ligand (HMBP).

Figure 3a shows the results of UV-vis spectra for the catalytic reduction of 4-nitrophenolate ions. The absorption intensity of 4-nitrophenolate ions at $400 \mathrm{~nm}$ decreased and on the other hand, the absorption of 4-aminophenol at $300 \mathrm{~nm}$ appeared. The observation of four isosbestic points demonstrates that no side products were produced [30]. Figure $3 b$ shows the ordinary absorption dependence over time for the reduction of 4-nitrophenolate ions at a wavelength of $400 \mathrm{~nm}$. In our case, contrary to what was observed by Wunder and co-workers $[12,13,16]$, no induction time was noticed. On the other hand, Menumerov showed that the induction period was linked to the level of dissolved oxygen contained in the medium [31]. He determined that the induction period ended once the level of dissolved oxygen fell below a critical value and that this level was dependent upon the metal nanoparticles used as a catalyst.

As can be seen, the reaction is stationary, and the linear fitting degree of $\ln \left(A / A_{0}\right)$ versus time follows pseudo first-order kinetics. The apparent kinetic rate constant $\left(k_{\text {app }}\right)$ was determined from linear regression using the following equation:

$$
\ln \left(\frac{A}{A_{0}}\right)=\ln \left(\frac{C}{C_{0}}\right)=k_{a p p} \cdot t
$$

where $A_{0}$ is the initial absorbance, and $A$ is the absorbance of 4-nitrophenolate ions at every time point. $C_{0}$ is the initial concentration, and $C$ is the concentration of 4-nitrophenolate ions in the reaction medium. According to the slope, the apparent rate constant is equal to $0.0006 \mathrm{~s}^{-1}$. 

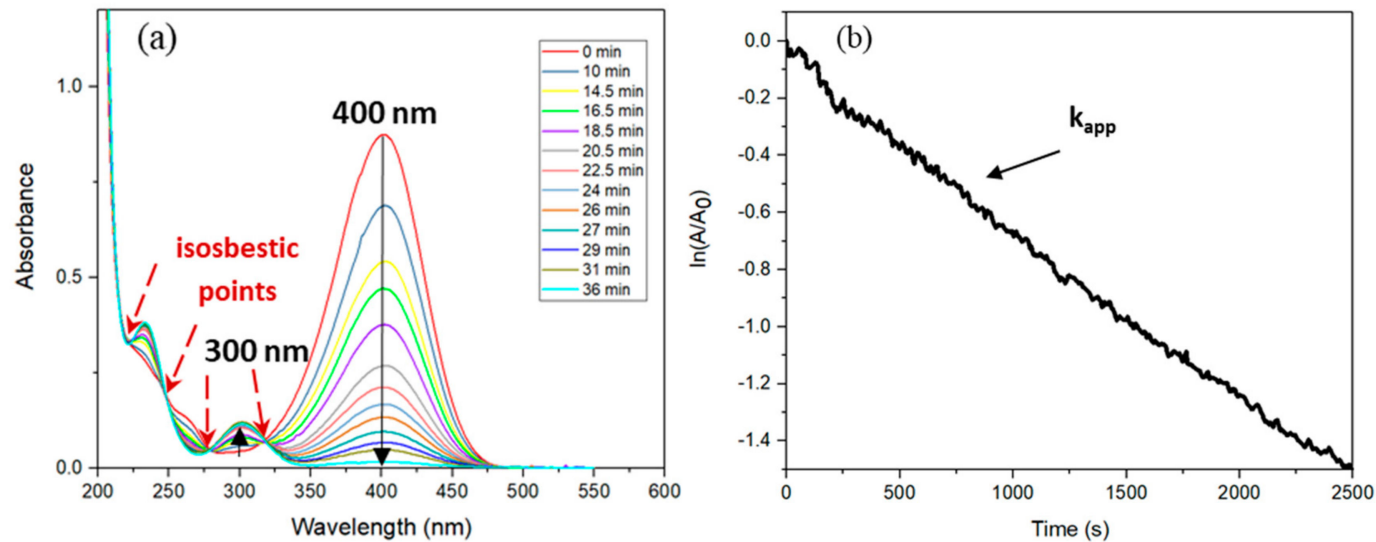

Figure 3. (a) Following UV-vis absorption spectra (6 s intervals) for the catalytic reduction of 4-Nip using $\mathrm{Pd}$ nanoparticles $(\mathrm{pH}=10)$. (b) Absorption dependence of the time for the reduction of 4-Nip. Conditions: $[4-\mathrm{Nip}]=7.38 \times 10^{-5} \mathrm{M} ;\left[\mathrm{NaBH}_{4}\right]=1.11 \times 10^{-2} \mathrm{M}(150$ eq (equivalent) $) ;[\mathrm{Pd}]=2.8 \times$ $10^{-5} \mathrm{M}(0.249 \mathrm{~mol} \% \mathrm{Pd}) ; \mathrm{T}=23.7^{\circ} \mathrm{C} .\left(k_{a p p}=0.0006 \mathrm{~s}^{-1}\right)$.

\subsection{Influence of Temperature (Derivation of Thermodynamic Parameters)}

The activation energy and thermodynamic parameters of the activation enthalpy and entropy for the reduction of 4-Nitrophenol by Pd nanoparticles were determined by conducting the reaction at various temperatures. As can be seen from Figure $4 \mathrm{a}$, the constant $k_{a p p}$ increases with increasing the temperature, which can be made clear by collision theory.
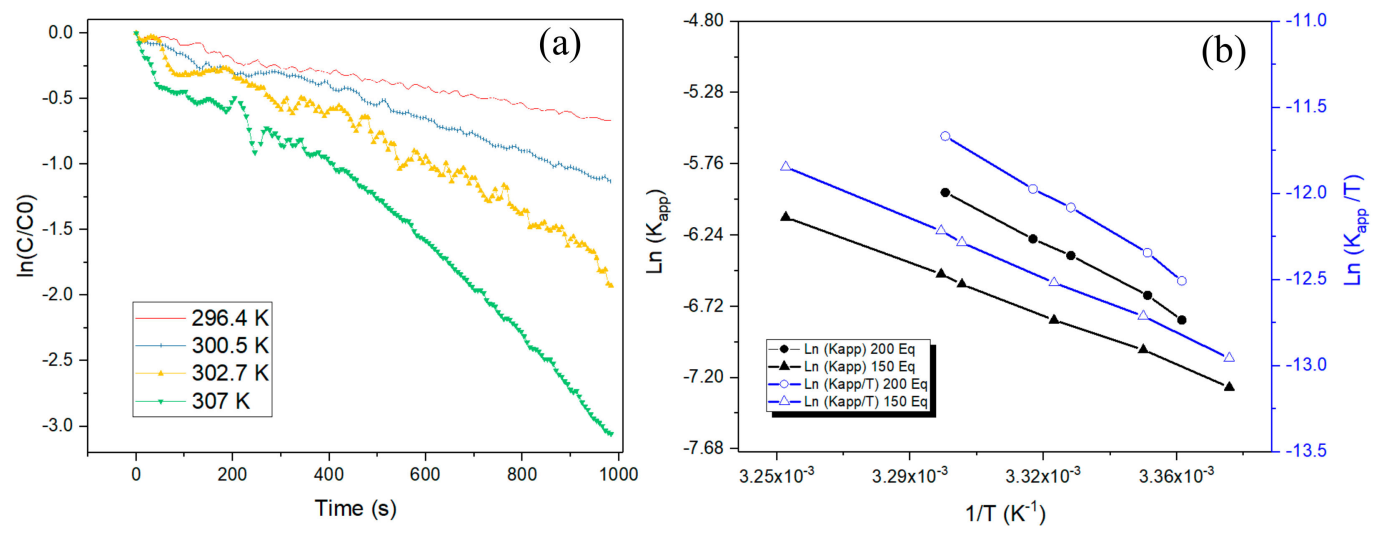

Figure 4. (a) $\ln \left(C / C_{0}\right)$ versus time at different reaction temperatures, conditions of reaction 150 eq $\mathrm{BH}_{4}{ }^{-}$; (b) Arrhenius plots $\ln \left(k_{\text {app }}\right)$ and Eyring plots $\ln \left(k_{\text {app }} / T\right)$ versus $1 / T$ for the Pd nanoparticles.

The movement of the 4-Nitrophenol molecule is considered to be vigorous, leading to a better chance for collision when we increase the temperature of the medium, which results in the rapid reaction rate [32]. The apparent activation energy $\left(E a_{a p p}\right)$, pre-exponential factor $A$, enthalpy $\left(\Delta \mathrm{H}^{\ddagger}\right)$, entropy $\left(\Delta S^{\ddagger}\right)$, and Gibbs energy of activation $\left(\Delta G^{\ddagger}\right)$ were calculated using the following equations:

Arrhenius equation:

$$
\ln \left(k_{\text {app }}\right)=\ln (A)-\frac{E a_{a p p}}{R T}
$$

Unimolecular reaction equation:

$$
A=e^{1} \cdot\left(\frac{k_{B} \cdot T^{\circ}}{h}\right) \cdot e^{\frac{\Delta S^{\ddagger}}{R}}
$$


Eyring equation:

$$
\ln \left(\frac{k_{\text {app }}}{T}\right)=-\frac{\Delta \mathrm{H}^{\ddagger}}{R} \cdot \frac{1}{T}+\frac{\Delta \mathrm{S}^{\ddagger}}{R}+\ln \left(\frac{k_{B}}{h}\right)
$$

Gibbs equation:

$$
\Delta G^{\ddagger}=\Delta H^{\ddagger}-T \times \Delta S^{\ddagger}
$$

where $R$ is the ideal gas constant $\left(R=8.314 \mathrm{~J} \cdot \mathrm{K}^{-1} \cdot \mathrm{mol}^{-1}\right), h$ is Planck's constant $\left(h=6.63 \times 10^{-34} \mathrm{~J} \cdot \mathrm{s}\right), k_{B}$ is the Boltzmann constant $\left(1.38 \times 10^{-23} \mathrm{~J} \cdot \mathrm{K}^{-1}\right), \mathrm{T}$ is the absolute temperature, and $\Delta \mathrm{H}^{\ddagger}, \Delta \mathrm{S}^{\ddagger}$, and $\Delta \mathrm{G}^{\ddagger}$ are the activation of enthalpy, entropy, and Gibbs energy, respectively.

As shown in Table 1, the apparent activation energy $\left(E a_{\text {app }}\right)$ was $81.22 \mathrm{~kJ} \cdot \mathrm{mol}^{-1}$ and $112.77 \mathrm{~kJ} \cdot \mathrm{mol}^{-1}$ for 150 and 200 equivalents of $\mathrm{NaBH}_{4}$, respectively, indicating that the apparent activation energy for the 4-Nip reduction was increased by increasing the $\mathrm{NaBH}_{4}$ equivalent. The $E a$ was affected by the concentration of sodium borohydride, which plays a critical role in the $\mathrm{pH}$ medium. The $\mathrm{pH}$ medium affects the overall rate constant and activation energy. In the case of $150 \mathrm{eq}$, the $\mathrm{pH}$ was 9.69, and in the case of 200 eq, the $\mathrm{pH}$ was 9.93. This slight change influenced the $\mathrm{NaBH}_{4}$ hydrolysis, which was faster, leading to higher formation of reactive Pd-H at the surface of NPs as described by Grzeschik and coworkers [33]. They found that the $\mathrm{pH}$ value has an influence on the kinetics of 4-Nip reduction and that by decreasing the initial $\mathrm{pH}$ value, the reaction becomes much faster. Consequently, by increasing the concentration of $\mathrm{NaBH}_{4}$ in the medium, we increased the hydrogen and hydride species formation in the medium, which led to the saturation of the surface of Pd NPs $(\mathrm{Pd}-\mathrm{H})$ followed by increased $E a$.

\begin{tabular}{|c|c|c|c|c|c|}
\hline $\mathrm{BH}_{4}^{-}$ & $E a_{a p p}\left(\mathrm{~kJ} \cdot \mathrm{mol}^{-1}\right)$ & $A$ & $\Delta \mathrm{H}^{\ddagger}\left(\mathrm{kJ} \cdot \mathrm{mol}^{-1}\right)$ & $\begin{array}{c}\Delta S^{\ddagger} \\
\left(\mathrm{J} \cdot \mathrm{mol}^{-1} \cdot \mathrm{K}^{-1}\right)\end{array}$ & $\Delta \mathrm{G}^{\ddagger}\left(\mathrm{kJ} \cdot \mathrm{mol}^{-1}\right)$ \\
\hline $150 \mathrm{eq}$ & 81.22 & $1.46 \times 10^{11}$ & 78.68 & -39.57 & 90.47 \\
\hline $200 \mathrm{eq}$ & 112.77 & $7.13 \times 10^{16}$ & 110.22 & 69.36 & 89.56 \\
\hline
\end{tabular}

Table 1. The result of thermodynamic parameters for 150 eq and 200 eq of $\mathrm{BH}_{4}{ }^{-}$for Reduction of 4-Nip.

The $E a$ value was relatively similar for reactions over platinum and/or palladium nanocages (NCs). It was comparable to the values reported for the reduction of 4-Nip over Pt-Pd alloy NCs $\left(109.6 \mathrm{~kJ} \cdot \mathrm{mol}^{-1}\right)$ and Pd NCs $\left(94.5 \mathrm{~kJ} \cdot \mathrm{mol}^{-1}\right)$ [34].

According to the plot of $\ln \left(k_{\text {app }} / T\right)$ versus $1 / T$, we found the values of $\Delta \mathrm{H}^{\ddagger}$ positive for both cases (150 eq and $200 \mathrm{eq}$ ), which means that the 4-nitrophenol reduction is endothermic [19,35] due to the fact that the product, 4-aminophenol, has greater enthalpy than the reactant, 4-nitrophenol. The value of $\Delta \mathrm{S}^{\ddagger}$ provides an indication of the molecularity of the rate-determining step, that is to say if the reactants are bound to each other or not. We noticed a negative value of $\Delta \mathrm{S}^{\ddagger}$ in the case of $150 \mathrm{eq}$, which signifies that entropy decreased as more ordered structures for the transition state were formed. This frequently indicates an associative mechanism of the adsorption of 4-nitrophenol as well as $\mathrm{BH}_{4}{ }^{-}$on the surface of Pd nanoparticles to form a single activated complex [36,37]. In the case of 200 eq, we obtained a positive value, indicating an increase in achieving the transition state, which frequently signifies a dissociative mechanism in which the activated complex is loosely bound and about to dissociate. This change in $\Delta S \ddagger$ is due to the compensation effect between the transition state entropy and enthalpy that was observed by Corma et al. [38]. Generally, the compensation effect has been explained by many effects such as the relationship between the coverage of the surface and activation energy [39,40], entropy-enthalpy relationship [39,41], and many other effects that were further investigated by Bond et al. in their article review [39].

The Gibbs free energy of activation $\Delta \mathrm{G}^{\ddagger}$ was determined at $25^{\circ} \mathrm{C}$; this free-energy indicates the barrier to move from the 4-nitrophenol state to the activated state. We found almost the same values, $90.47 \mathrm{~kJ} \cdot \mathrm{mol}^{-1}$ and $89.56 \mathrm{~kJ} \cdot \mathrm{mol}^{-1}$, for $150 \mathrm{eq}$ and $200 \mathrm{eq}$, respectively, which means that reduction of 4-nitrophenol to 4-aminophenol required the same energy. 


\subsection{Effects of Surface Area and Concentration of Reagents}

Many authors have reported that the amount of nanocatalyst, the initial concentration of 4-nitrophenol, and $\mathrm{NaBH}_{4}$ are important factors that influence the catalytic reduction of 4-nitrophenol to 4-aminophenol by a metal nanoparticle [12,13,42,43]. To study the effect on the apparent rate constant $\left(k_{a p p}\right)$ at $25.5^{\circ} \mathrm{C}$, the experiments were carried out by varying a single factor of the initial amounts of the nanocatalyst, 4-nitrophenol, and $\mathrm{NaBH}_{4}$ concentration.

Furthermore, each number of active sites that exist at the surface of nanoparticles is proportional to the amount of Pd nanoparticles used. In this manner, as predicted, Figure 5b shows that the value of $k_{a p p}$ and the initial velocity increase with an increase in the amount of the nanocatalyst.
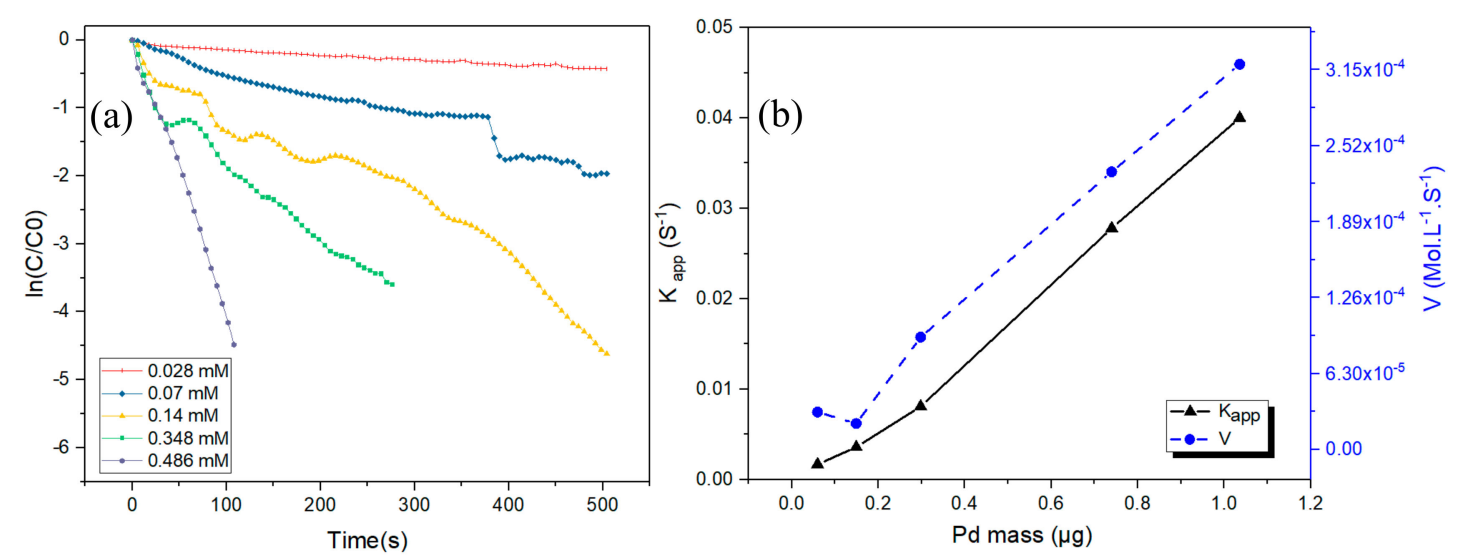

Figure 5. (a) $\ln \left(C / C_{0}\right)$ versus time at different concentrations of Pd nanoparticles. (b) Plots of $k_{a p p}$ and initial velocity (rate) versus the amount of $\mathrm{Pd}$ nanocatalyst; conditions of the reaction at 150 eq $\mathrm{NaBH}_{4}$; $[4-\mathrm{NIP}]=7.38 \times 10^{-5} \mathrm{M}$; temperature $25.5^{\circ} \mathrm{C}$.

Figure $6 \mathrm{a}, \mathrm{b}$ display the plots of $k_{a p p}$ at different initial 4-nitrophenol concentrations and the surface area, respectively. As we noticed from Figure $6 \mathrm{a}$, the value of $k_{a p p}$ decreased in the case of increasing the initial 4-nitrophenol concentration. Up to certain concentrations and surface areas, the constant $k_{\text {app }}$ remained constant. The empirical model using classical methods of experimental kinetics is not valid since the constant $k_{a p p}$ is constant only for a well-defined area (from C4-nip ranging from 5 to $2 \times 10^{-4} \mathrm{M}$ ), and the active surface (quantity of nano of Pd) of $k_{a p p}$ is related to the surface area of the Pd nanoparticles.

To describe the model, we must turn to the Langmuir Hinshelwood model, which assumes that the adsorption of molecules onto the nanoparticles surface is fast and reversible.

The co-adsorption of 4-Nip and $\mathrm{NaBH}_{4}$ is required, as we assumed that all steps of this reaction proceed only on the surface-active sites of Pd nanoparticles (Langmuir-Hinshelwood model). However, when the initial 4-nitrophenol concentration in the solution is high, the active sites are mostly occupied by 4-nitrophenol molecules and a minority by active hydrogen species, which result in a low constant of the velocity of reaction. On the other hand, as the surface area increases and the initial concentration of 4-nitrophenol remains constant or decreases, following an increase in the $\mathrm{NaBH}_{4}$ to 4-Nip ratio, fewer 4-nitrophenol molecules adsorb on the surface because the majority of active sites are occupied by active hydrogen species, so the velocity of the reaction increases.

Figure $6 \mathrm{~b}$ shows the plot of the apparent kinetic rate constants obtained experimentally relative to the normalized surface area of $\mathrm{Pd}$ nanoparticles for different concentration ratios of $\mathrm{NaBH}_{4}$ to 4-Nip. As can be seen, the constant $k_{a p p}$ initially increased linearly with increasing surface area at a constant temperature and concentration ratio of $\mathrm{NaBH}_{4}$ to 4-Nip, which emphasizes the important effect of the amount of potential active sites based on the total surface area accessible for the catalytic reduction 
of 4-nitrophenol. The rate constant $k_{1}$ normalized to the surface area was determined graphically by the equation:

$$
k_{\text {app }}=k_{1} \cdot S
$$

In each graph, the linear fitting indicates the intrinsic kinetic region (straight lines); the rate constant $k_{1}$ normalized to the surface area was determined for each concentration ratio of $\mathrm{NaBH}_{4}$ to 4-Nip where 10,000 eq, 1000 eq, 400 eq, 201 eq, 100 eq, 67 eq, and 50 eq showed values of 2.5, 1.18, 0.78, $0.36,0.26,0.18$, and $0.13 \mathrm{~min} / \mathrm{m}^{2} \mathrm{~L}$, respectively. The rate constant $k_{1}$ normalized to the surface area showed a decrease in value from 10,000 eq to 50 eq. This was expected as the minority of active sites were occupied by active hydrogen species, so the velocity of the reaction decreased. The dashed lines represent the area where diffusion control takes place [8].
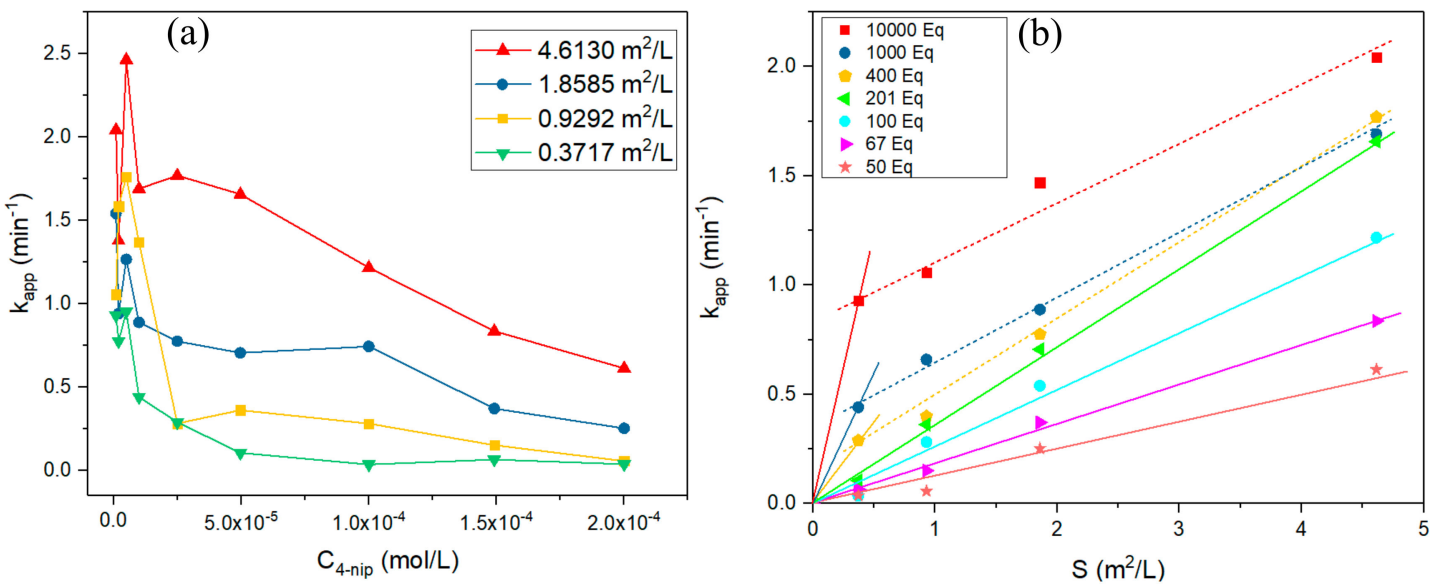

Figure 6. Plots of $k_{a p p}$ versus (a) the concentration of 4-nitrophenol at a constant temperature of $22.4{ }^{\circ} \mathrm{C}$ and concentration of $\mathrm{NaBH}_{4}$ of $1 \times 10^{-2} \mathrm{M}$ for four different surface areas of NPs Pd, $0.3717 \mathrm{~m}^{2} / \mathrm{L}$, $0.9292 \mathrm{~m}^{2} / \mathrm{L}, 1.8585 \mathrm{~m}^{2} / \mathrm{L}$, and $4.6130 \mathrm{~m}^{2} / \mathrm{L}$. (b) Surface area of Pd NPs at a constant temperature of $22.4{ }^{\circ} \mathrm{C}$ for seven different equivalents of $\mathrm{NaBH}_{4}$ 10,000 eq, 1000 eq, $400 \mathrm{eq}, 201 \mathrm{eq}, 100 \mathrm{eq}, 67 \mathrm{eq}$, and 50 eq. The straight lines illustrate the intrinsic kinetic area, and the dashed lines illustrate the area where diffusion limitations take place.

The diffusion control is a significant factor that must be taken into consideration in the kinetic studies of a catalytic reaction. The reactions occur only on the surface-active sites of $\mathrm{Pd}$ nanoparticles according to the Langmuir-Hinshelwood model. Therefore, when the rate of the reaction is significantly faster than the diffusion of the 4-nitrophenol molecules, the reaction is controlled by diffusion, and the constant $k_{\text {app }}$ notably includes the rate of diffusion of the 4-nitrophenol molecules through the medium. On the other hand, when the diffusion rate is faster than the rate of the reaction, the reaction is kinetically controlled, and the constant $k_{a p p}$ only indicates the rate-determining step.

The ratio of these two rates can be described by the second Damköhler (DaII) equation [44]:

$$
\text { DaII }=\frac{\text { chemical reaction rate }}{\text { mass transfer rate }}=\frac{k_{\text {app }}[4-N i p]^{n-1}}{\beta \alpha}
$$

where $k_{a p p}$ is the apparent rate constant, $\mathrm{n}$ is the order of the reaction (first-order for 4-Nip), $\alpha$ is the interfacial area, which is the volume-normalized area of the Pd nanoparticles [19], and $\beta$ is the mass transport coefficient, defined as the ratio of $D$, the diffusion coefficient of 4-Nip $\left(6.92 \times 10^{-10} \mathrm{~m}^{2} / \mathrm{s}\right)$ [45], to $\delta$, the characteristic diffusion length, which is determined by DLS as the hydrodynamic radius of our Pd nanoparticles. The summary of these parameters for a different amount of Pd nanoparticles and two equivalents of $\mathrm{NaBH}_{4}$ is presented in Table 2. 
Table 2. The summary of DaII Parameter Values for different amounts of Pd NPs at two $\mathrm{NaBH}_{4}$ equivalents.

\begin{tabular}{|c|c|c|c|c|c|c|}
\hline$a\left(\mathrm{~m}^{-1}\right)$ & $\beta(\mathrm{m} / \mathrm{s})$ & $\delta(\mathrm{nm})$ & $\begin{array}{c}k_{a p p}{ }^{\mathrm{a}} \\
\left(\times 10^{-3} \mathrm{~s}^{-1}\right)\end{array}$ & $\begin{array}{c}\mathrm{DaII}^{\mathrm{a}} \\
\left(\times 10^{-4}\right)\end{array}$ & $\begin{array}{c}k_{\text {app }} \mathrm{b} \\
\left(\times 10^{-3} \mathrm{~s}^{-1}\right)\end{array}$ & $\begin{array}{c}\text { DaII }^{b} \\
\left(\times 10^{-4}\right)\end{array}$ \\
\hline 4613.1 & 0.077 & 9.045 & 34.05 & 0.965 & 10.23 & 0.290 \\
\hline 1858.5 & 0.077 & 9.045 & 24.50 & 1.723 & 4.22 & 0.297 \\
\hline 929.3 & 0.077 & 9.045 & 17.62 & 2.478 & 0.95 & 0.134 \\
\hline 371.7 & 0.077 & 9.045 & 0.55 & 5.453 & 0.02 & 0.221 \\
\hline
\end{tabular}

Figure $7 \mathrm{a}, \mathrm{b}$ display the plots of DaII at different $k_{a p p}$ and surface area values for different concentration ratios of $\mathrm{NaBH}_{4}$ to 4-Nip, respectively.
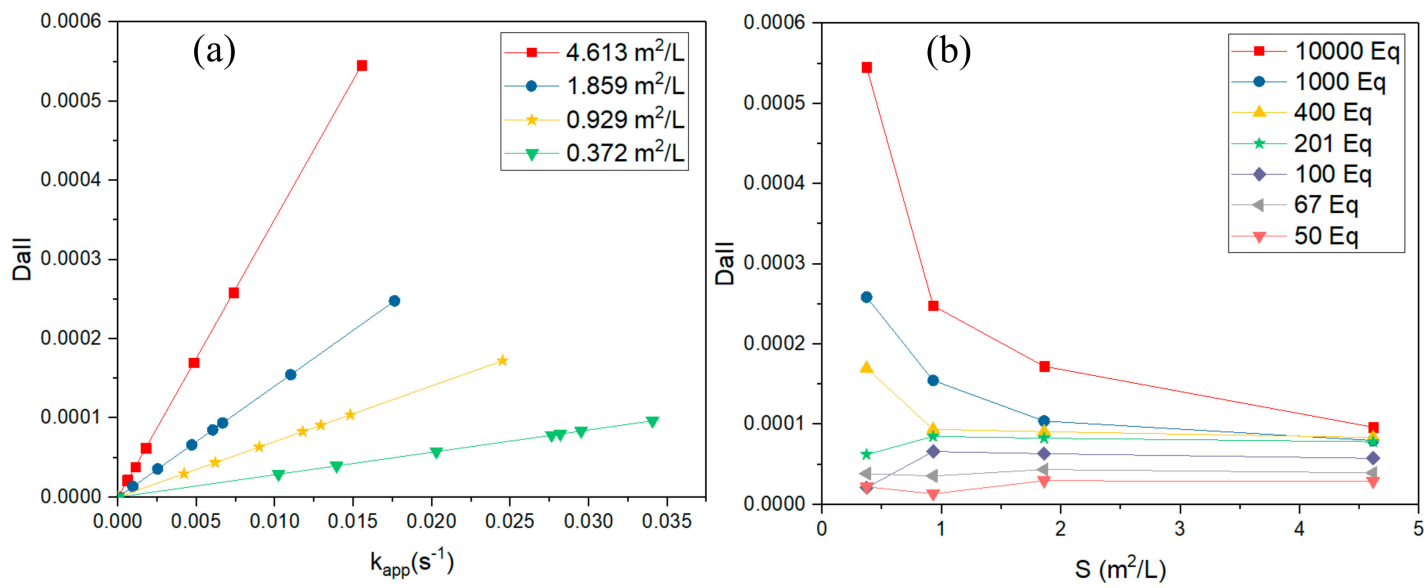

Figure 7. Plots of DaII versus different (a) apparent rate constants, $k_{a p p}$, at a constant temperature of $22.4{ }^{\circ} \mathrm{C}$ and concentration of $\mathrm{NaBH}_{4}$ of $1 \times 10^{-2} \mathrm{M}$ at four different surface areas of Pd NPs, $0.3717 \mathrm{~m}^{2} / \mathrm{L}$, $0.9292 \mathrm{~m}^{2} / \mathrm{L}, 1.8585 \mathrm{~m}^{2} / \mathrm{L}$, and $4.6130 \mathrm{~m}^{2} / \mathrm{L}$. (b) Surface area of NP Pd at a constant temperature of $22.4{ }^{\circ} \mathrm{C}$ for seven different equivalents of $\mathrm{NaBH}_{4}: 10,000 \mathrm{eq}, 1000 \mathrm{eq}, 400 \mathrm{eq}, 201 \mathrm{eq}, 100 \mathrm{eq}, 67 \mathrm{eq}$, and $50 \mathrm{eq}$.

Figure 7a shows that the value of DaII increased in the case of the increase of the apparent rate constant $k_{\text {app }}$ at a constant surface area of Pd NPs. On the other hand, we noticed from Figure $7 \mathrm{~b}$ that the value of the second Damköhler number decreased when we increased the surface area of Pd NPs for all cases until this number remained constant at a higher surface area. This result was expected since the initial concentration of $\mathrm{NaBH}_{4}$ was higher than that of 4-nitrophenol, and a lower surface area allows more active sites to be occupied by active hydrogen species.

The calculations of the second Damköhler number from 50 until 10,000 equivalents of $\mathrm{NaBH}_{4}$ showed values in the order of $10^{-4}$ or less. The diffusion control was negligible in all cases by reason that the values obtained were lower than 1 (DaII $<<1)$, so the diffusion rate was much faster than the rate of reaction $[8,46]$.

\subsection{Influence of Reagent Concentration (Derivation of the Langmuir-Hinshelwood Parameters)}

We investigated the fitting of the Langmuir-Hinshelwood model (Equation (1)) to experimental data determine by the temporal decay of the concentration of 4-Nip. Two different experiments were run at four different temperatures; by using Pd nanoparticle catalysts, the initial concentration of 4-Nip was set constant $\left(7.38 \times 10^{-5} \mathrm{M}\right)$, and the initial concentration of $\mathrm{BH}_{4}{ }^{-}$was varied from 150 to 200 eq.

Figure 8 displays the fits of Langmuir-Hinshelwood model to the experimental data at different temperatures. All curves were plot to a conversion of $60 \%$ to make sure of the significance of the comparison. The dashed lines are the experimental concentrations of 4-Nip, and the solid lines are the fits from the Langmuir-Hinshelwood model. As can be seen, $\mathrm{C}_{4-\mathrm{Nip} \text {,ther }}$ deviates from $\mathrm{C}_{4-\mathrm{Nip} \text {,exp }}$ at 
higher temperatures and longer reaction time, which is expected from inescapable side reaction of $\mathrm{BH}_{4}{ }^{-}$hydrolysis [31,32], resulting in the shift of $\mathrm{C}_{4-\mathrm{Nip} \text {,exp }}$ throughout the measurements.
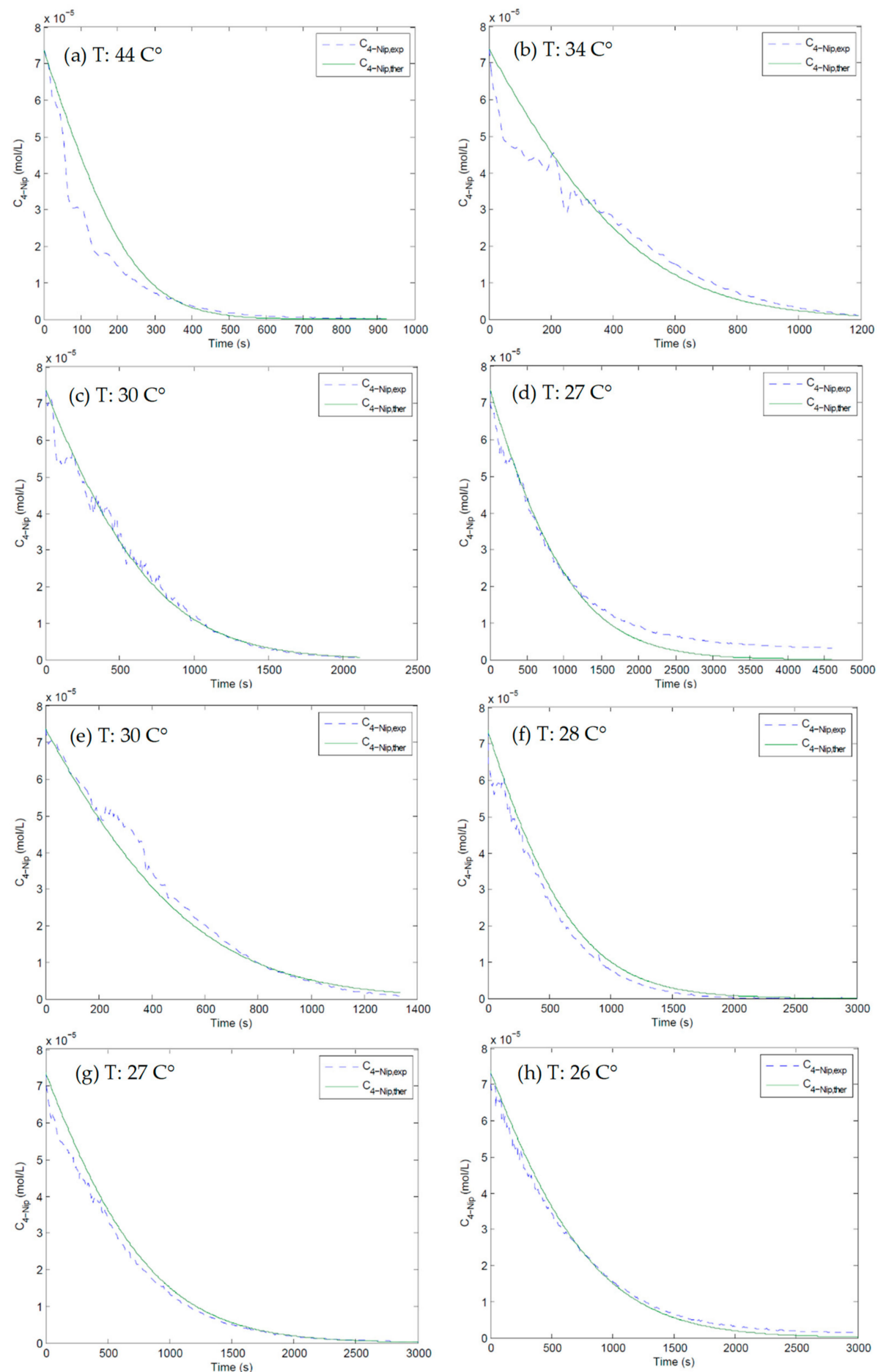

Figure 8. Plots of the concentration of 4-Nip as a function of time at different temperatures by using the Langmuir-Hinshelwood model. The solid green lines represent the respective fits to the kinetic model. The amount of $\mathrm{BH}_{4}{ }^{-}$used was $150 \mathrm{eq}$ and 200 eq for graphs (a-d) and (e-h), respectively.

The corresponding fit parameters are presented in Table 3. These parameters were determined using a numerical solution of Equation (1) by a MatLab routine. Apparently, a single set of the rate constant $k$ and the adsorption constants $K_{4-N i p}$ and $K_{B H 4-}$ is able to represent the experimental data at 
a specific temperature. The value of the adsorption constant $K_{4-N i p}$ is much higher than that of $K_{B H 4-}$ and increases with temperature, while $\mathrm{K}_{\mathrm{BH} 4}$ remained almost constant in the same temperature range (see Figure 9). This explains why the 4-nitrophenol molecules were more strongly adsorbed on the surface of the Pd nanoparticles than the borohydride ions. On the other hand, Guella and Liu showed that the interaction of borohydride ions with metal surfaces is a complex process that involves several steps $[26,27]$.

Table 3. The result of the rate constant $\mathrm{k}$ and the adsorption constants $K_{4-\mathrm{Nip}}$ and $K_{B H 4-}$ at different temperatures from fitting the experimental Data with the Langmuir-Hinshelwood model.

\begin{tabular}{cccc}
\hline $\boldsymbol{T}(\mathbf{K})$ & $\boldsymbol{k}\left(\mathbf{m o l} / \mathbf{m}^{2} \cdot \mathbf{s}\right)$ & $\boldsymbol{K}_{\mathbf{4 - N i p}}(\mathrm{L} / \mathbf{m o l})$ & $\boldsymbol{K}_{\mathbf{B H} \mathbf{-}}(\mathbf{L} / \mathbf{m o l})$ \\
\hline 317 & 0.02 & 8900 & 2.45 \\
307 & 0.0115 & 6300 & 2.34 \\
303 & 0.0083 & 5200 & 2.3 \\
301 & 0.007 & 4800 & 2.28 \\
300 & 0.006 & 4600 & 2.27 \\
297.8 & 0.005 & 4200 & 2.25 \\
296.3 & 0.0037 & 3900 & 2.235 \\
\hline
\end{tabular}

Table 4. Summary of thermodynamic parameters for the adsorption process of 4-Nip and $\mathrm{BH}_{4}{ }^{-}$

\begin{tabular}{ccc}
\hline & $\boldsymbol{K}_{4-N i p}$ & $\boldsymbol{K}_{\mathbf{B H 4 ^ { - }}}$ \\
\hline$\Delta \mathrm{H}_{\mathrm{ad}}[\mathrm{kJ} / \mathrm{mol}]$ & 30.87 & 3.31 \\
$\Delta \mathrm{S}_{\mathrm{ad}}[\mathrm{J} / \mathrm{mol} \mathrm{K}]$ & 173 & 17.8 \\
\hline
\end{tabular}
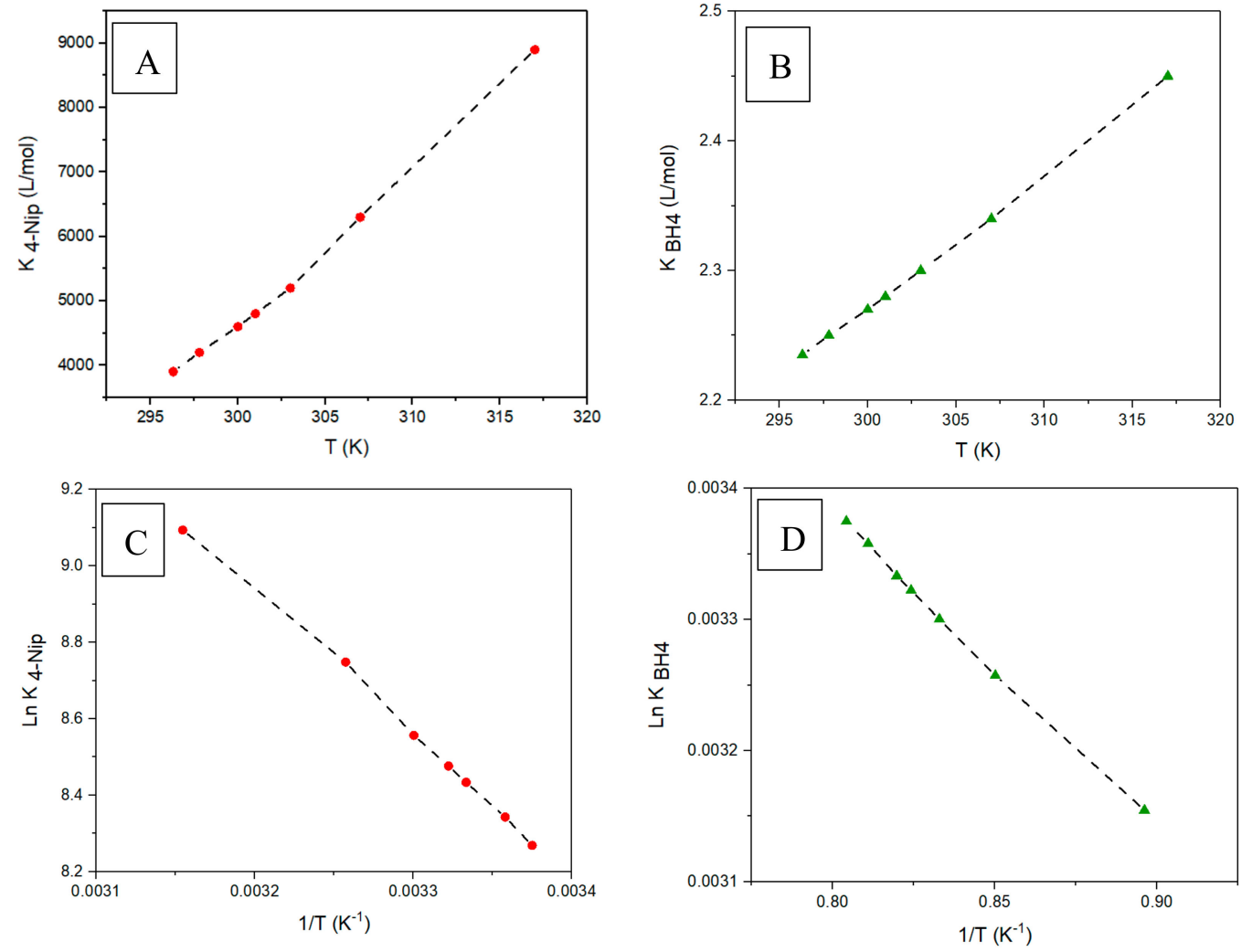

Figure 9. Plots of the adsorption constant $K_{4-N i p}$ of 4-Nip (A) and the adsorption constant $\mathrm{K}_{\mathrm{BH} 4}{ }^{-}$of $\mathrm{BH}_{4}{ }^{-} ;(\mathbf{B})$ versus temperature. The enthalpies and entropies of the adsorption process were calculated from $\ln \left(K_{4-N i p}\right)$ (C) and $\ln \left(K_{B H 4}{ }^{-}\right)$(D) based on the inverse of temperature using the van't Hoff equation. All values are given in Table 4. 
Furthermore, the true rate constant $\mathrm{k}$ increased with an increase in the temperature, and the true activation energy Ea obtained from the Arrhenius plot was $61 \mathrm{~kJ} \cdot \mathrm{mol}^{-1}$ (Figure 10). This true activation energy is the same order of magnitude as that of apparent activation energy $E a_{a p p}\left(81.22 \mathrm{~kJ} \cdot \mathrm{mol}^{-1}\right)$ determined at $150 \mathrm{eq}$ of $\mathrm{BH}_{4}{ }^{-}$and is correlated with the reaction of the surface-bound species with adsorbed 4-nitrophenol. On the other hand, $E a_{a p p}$ is just an apparent value as it contains the adsorption constants $\mathrm{K}_{4-\mathrm{Nip}}$ and $\mathrm{K}_{\mathrm{BH} 4}{ }^{-}$, which depend on the temperature.

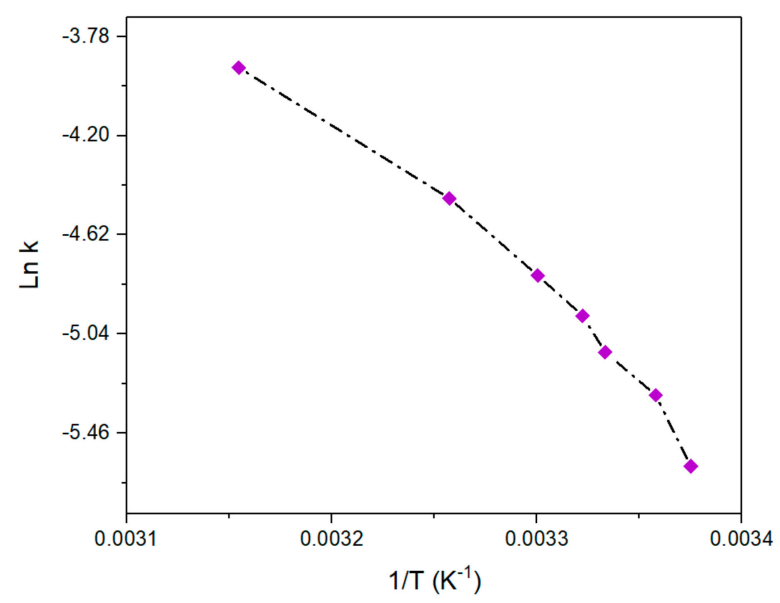

Figure 10. Arrhenius plots of $\ln \mathrm{k}$ versus $1 / \mathrm{T}$ for the Pd nanoparticles at a constant concentration of 4-nitrophenol $\left(7.38 \times 10^{-5} \mathrm{M}\right)$ and $\mathrm{NaBH}_{4}(150 \mathrm{eq})$. The rate constant $k$ is obtained from fitting the experimental data with the Langmuir-Hinshelwood model (see Table 3).

The values of thermodynamic parameters for the adsorption process of 4-Nip and $\mathrm{BH}_{4}{ }^{-}$are given in Table 4. All enthalpy and entropy values of the adsorption of 4-Nip and $\mathrm{BH}_{4}^{-}$are positive. The adsorption entropy indicates that the release of water or other surface-bound species is the dominating process of adsorption [12]. These enthalpy and entropy adsorption values are in a similar range of what Wunder and coworkers found by using Gold NPs [12].

\section{Conclusions}

In summary, "water-soluble" Palladium Nanoparticles exhibit high catalytic performance for catalytic reduction of 4-nitrophenol by using sodium borohydride as the reducer in comparison to many various mNP catalysts reported in the literature (see Table 2 of the review [47]). All kinetics of the reduction process were studied by varying a single factor each time, i.e., the amount of $\mathrm{Pd}$ nanoparticles, initial 4-nitrophenol, and $\mathrm{NaBH}_{4}$ concentration under various experimental conditions.

The evaluation of diffusion control was conducted by the calculation of the second Damköhler number. In this study, we found that the more we increased the concentration of $\mathrm{NaBH}_{4}$ in a small surface area of Pd nanoparticles, the more the second Damköhler number increased. However, under this condition, the catalytic systems were not controlled by the diffusion of reactants to the surface of the nanoparticles because the values obtained were always lower than 1 (DaII $<<1$ ).

A schematic representation of the Langmuir-Hinshelwood mechanism of 4-Nip reduction on the surface of Pd nanoparticles has been presented, and kinetic evaluation of the fitting of experimental data to the theoretical values has been done in the intrinsic kinetic area by using the Langmuir-Hinshelwood equation. The theoretical values obtained from the Langmuir-Hinshelwood equation were successfully fitted to the experimental data, and the true rate constant $k$, as well as the adsorption constants of 4-Nip and $\mathrm{BH}_{4}{ }^{-}$, were determined for each temperature.

The Arrhenius analysis of $\ln \mathrm{k}$ of the inverse of the temperature led to the value of the true activation energy $E a\left(61 \mathrm{~kJ} \cdot \mathrm{mol}^{-1}\right)$ of the true rate constant $\mathrm{k}$. However, the thermodynamic parameters of the adsorption enthalpy $\Delta \mathrm{H}$ and entropy $\Delta \mathrm{S}$ for both reactants were determined since they depend 
on the temperature. Moreover, the thermodynamic parameters including the apparent activation energy $\left(E a_{a p p}\right)$, pre-exponential factor A, activation of enthalpy $\Delta \mathrm{H}^{\ddagger}$, entropy $\Delta \mathrm{S}^{\ddagger}$, and Gibbs energy $\Delta \mathrm{G}^{\ddagger}$ were obtained by conducting the reaction at various temperatures and by using Arrhenius, Eyring, and Gibbs equations. The values of these thermodynamic parameters are in agreement of what is reported in the literature [19].

The results show that to compare the catalytic performance of mNPs, the reactions conditions should be the same such as using a small amount of mNPs, and the ratio of sodium borohydride to the 4-Nip concentration should be between 200 to 60 eq, so that apparent rate constant " $k_{a p p}$ " remains constant and is not strongly affected by these conditions parameters. Therefore, it appears that there is a crucial need for standardization of reaction conditions for a fair comparison of the catalytic performance of mNPs.

Supplementary Materials: The following are available online at http://www.mdpi.com/2079-4991/10/6/1169/s1, The calculation of the surface area of the Pd nanoparticles, The general preparation of the Pd nanoparticles, The simulation of Langmuir-Hinshelwood equation with the MatLab routine used.

Author Contributions: A.I.A. conceived and designed the experiments; A.I.A. performed the experiments and analyzed the data; A.I.A., A.O.D., D.L. and E.G. provided the concept of this research and managed all the experimental and writing process as the corresponding authors; all authors discussed the results and commented on the manuscript. All authors have read and agreed to the published version of the manuscript.

Funding: This research received no external funding.

Acknowledgments: The research described here was sponsored by the European Union (FEDER) and the Région Haut de France and the Université de Technologie de Compiègne through funding of the chair: "Green Chemistry and Processes".

Conflicts of Interest: The authors declare no conflict of interest.

\section{References}

1. Ferrando, R.; Jellinek, J.; Johnston, R.L. Nanoalloys: From theory to applications of alloy clusters and nanoparticles. Chem. Rev. 2008, 108, 845-910. [CrossRef] [PubMed]

2. Zahmakıran, M.; Özkar, S. Metal nanoparticles in liquid phase catalysis; from recent advances to future goals. Nanoscale 2011, 3, 3462. [CrossRef] [PubMed]

3. Astruc, D. Transition-metal nanoparticles in catalysis: From historical background to the state-of-the art. Nanoparticles Catal. 2008, 16, 1-48.

4. Sardar, R.; Funston, A.M.; Mulvaney, P.; Murray, R.W. Gold nanoparticles: Past, present, and future. Langmuir 2009, 25, 13840-13851. [CrossRef] [PubMed]

5. Reiss, H. The Fermi level and the redox potential. J. Phys. Chem. 1985, 89, 3783-3791. [CrossRef]

6. Khan, S.U.M.; Kainthla, R.C.; Bockris, J.O.M. The redox potential and the Fermi level in solution. J. Phys. Chem. 1987, 91, 5974-5977. [CrossRef]

7. Pradhan, N.; Pal, A.; Pal, T. Silver nanoparticle catalyzed reduction of aromatic nitro compounds. Colloids Surf. A Physicochem. Eng. Asp. 2002, 196, 247-257. [CrossRef]

8. Antonels, N.C.; Meijboom, R. Preparation of Well-De fi ned Dendrimer Encapsulated Ruthenium Nanoparticles and Their Evaluation in the Reduction of 4-Nitrophenol According to the LangmuirHinshelwood Approach. Langmuir 2013, 29, 13433-13442. [CrossRef]

9. Chen, J.; Song, M.; Li, Y.; Zhang, Y.; Taya, K.; Li, C.M. The effect of phytosterol protects rats against 4-nitrophenol-induced liver damage. Environ. Toxicol. Pharmacol. 2016, 41, 266-271. [CrossRef]

10. Narayanan, K.B.; Sakthivel, N. Synthesis and characterization of nano-gold composite using Cylindrocladium floridanum and its heterogeneous catalysis in the degradation of 4-nitrophenol. J. Hazard. Mater. 2011, 189, 519-525. [CrossRef]

11. Hervés, P.; Pérez-Lorenzo, M.; Liz-Marzán, L.M.; Dzubiella, J.; Lu, Y.; Ballauff, M. Catalysis by metallic nanoparticles in aqueous solution: Model reactions. Chem. Soc. Rev. 2012, 41, 5577-5587. [CrossRef] [PubMed]

12. Wunder, S.; Lu, Y.; Albrecht, M. Catalytic activity of facetted gold nanoparticles studied by a model reaction: Evidence for substrate-induced surface restructuring. ACS Catal. 2011, 1, 908-916. [CrossRef] 
13. Wunder, S.; Polzer, F.; Lu, Y.; Mei, Y.; Ballauff, M. Kinetic analysis of catalytic reduction of 4-nitrophenol by metallic nanoparticles immobilized in spherical polyelectrolyte brushes. J. Phys. Chem. C. 2010, 114, 8814-8820. [CrossRef]

14. Mahmoud, M.A.; Garlyyev, B.; El-Sayed, M.A. Determining the mechanism of solution metallic nanocatalysis with solid and hollow nanoparticles: Homogeneous or heterogeneous. J. Phys. Chem. C 2013, 117, 21886-21893. [CrossRef]

15. Iben Ayad, A.; Belda Marín, C.; Colaco, E.; Lefevre, C.; Méthivier, C.; Ould Driss, A.; Landoulsi, J.; Guénin, E. "water soluble" palladium nanoparticle engineering for $\mathrm{C}-\mathrm{C}$ coupling, reduction and cyclization catalysis. Green Chem. 2019, 21, 6646-6657. [CrossRef]

16. Gu, S.; Wunder, S.; Lu, Y.; Ballauff, M.; Fenger, R.; Rademann, K.; Jaquet, B.; Zaccone, A. Kinetic analysis of the catalytic reduction of 4-nitrophenol by metallic nanoparticles. J. Phys. Chem. C 2014, 118, 18618-18625. [CrossRef]

17. Behrens, S.; Heyman, A.; Maul, R.; Essig, S.; Steigerwald, S.; Quintilla, A.; Wenzel, W.; Bürck, J.; Dgany, O.; Shoseyov, $\mathrm{O}$. Constrained synthesis and organization of catalytically active metal nanoparticles by self-assem bled protein templates. Adv. Mater. 2009, 21, 3515-3519. [CrossRef]

18. Pradhan, N.; Pal, A.; Pal, T. Catalytic reduction of aromatic nitro compounds by coinage metal nanoparticles. Langmuir 2001, 17, 1800-1802. [CrossRef]

19. Bingwa, N.; Meijboom, R. Kinetic evaluation of dendrimer-encapsulated palladium nanoparticles in the 4-nitrophenol reduction reaction. J. Phys. Chem. C 2014, 118, 19849-19858. [CrossRef]

20. Tang, S.; Vongehr, S.; Meng, X. Controllable incorporation of Ag and Ag-Au nanoparticles in carbon spheres for tunable optical and catalytic properties. J. Mater. Chem. 2010, 20, 5436-5445. [CrossRef]

21. Zhang, Z.; Shao, C.; Sun, Y.; Mu, J.; Zhang, M.; Zhang, P.; Guo, Z.; Liang, P.; Wanga, C.; Liu, Y. Tubular nanocomposite catalysts based on size-controlled and highly dispersed silver nanoparticles assembled on electrospun silica nanotubes for catalytic reduction of 4-nitrophenol. J. Mater. Chem. 2012, 22, 1387-1395. [CrossRef]

22. Huang, J.; Vongehr, S.; Tang, S.; Lu, H.; Meng, X. Highly Catalytic Pd-Ag Bimetallic Dendrites. J. Phys. Chem. C 2010, 114, 15005-15010. [CrossRef]

23. Zhang, J.S.; Delgass, W.N.; Fisher, T.S.; Gore, J.P. Kinetics of Ru-catalyzed sodium borohydride hydrolysis. J. Power Sources 2007, 164, 772-781. [CrossRef]

24. Kong, X.; Zhu, H.; Chen, C.L.; Huang, G.; Chen, Q. Insights into the reduction of 4-nitrophenol to 4-aminophenol on catalysts. Chem. Phys. Lett. 2017, 684, 148-152. [CrossRef]

25. Tewari, B.B.; Boodhoo, M. Removal of p-aminophenol and p-nitrophenol from aqueous solution through adsorption on antimony, cadmium, and zirconium ferrocyanides. J. Colloid Interface Sci. 2005, 289, 328-332. [CrossRef]

26. Guella, G.; Patton, B.; Miotello, A. Kinetic features of the platinum catalyzed hydrolysis of sodium borohydride from 11B NMR measurements. J. Phys. Chem. C 2007, 111, 18744-18750. [CrossRef]

27. Liu, B.H.; Li, Z.P. A review: Hydrogen generation from borohydride hydrolysis reaction. J. Power Sources 2009, 187, 527-534. [CrossRef]

28. Rill, C.; Kolar, Z.I.; Kickelbick, G.; Wolterbeek, H.T.; Peters, J.A. Kinetics and thermodynamics of adsorption on hydroxyapatite of the [160Tb]terbium complexes of the bone-targeting ligands DOTP and BPPED. Langmuir 2009, 25, 2294-2301. [CrossRef]

29. László, K.; Podkościelny, P.; Dabrowski, A. Heterogeneity of polymer-based active carbons in adsorption of aqueous solutions of phenol and 2,3,4-trichlorophenol. Langmuir 2003, 19, 5287-5294. [CrossRef]

30. Mei, Y.; Lu, Y.; Polzer, F; Ballauff, M.; Drechsler, M. Catalytic Activity of Palladium Nanoparticles Encapsulated in Spherical Polyelectrolyte Brushes and Core-Shell Microgels. Chem. A Eur. J. 2007, 19, 1062-1069. [CrossRef]

31. Menumerov, E.; Hughes, R.A.; Neretina, S. Catalytic Reduction of 4-Nitrophenol: A Quantitative Assessment of the Role of Dissolved Oxygen in Determining the Induction Time. Nano Lett. 2016, 16, 7791-7797. [CrossRef] [PubMed]

32. Nemanashi, M.; Meijboom, R. Synthesis and characterization of Cu, Ag and Au dendrimer-encapsulated nanoparticles and their application in the reduction of 4-nitrophenol to 4-aminophenol. J. Colloid Interface Sci. 2013, 389, 260-267. [CrossRef] [PubMed] 
33. Grzeschik, R.; Schäfer, D.; Holtum, T.; Küpper, S.; Hoffmann, A.; Schlücker, S. On the Overlooked Critical Role of the $\mathrm{pH}$ Value on the Kinetics of the 4-Nitrophenol $\mathrm{NaBH}_{4}$-Reduction Catalyzed by Noble-Metal Nanoparticles (Pt, Pd, and Au). J. Phys. Chem. C 2020, 124. [CrossRef]

34. Mahmoud, M.A.; Saira, F.; El-Sayed, M.A. Experimental evidence for the nanocage effect in catalysis with hollow nanoparticles. Nano Lett. 2010, 10, 3764-3769. [CrossRef]

35. Noh, J.H.; Meijboom, R. Catalytic evaluation of dendrimer-templated Pd nanoparticles in the reduction of 4-nitrophenol using Langmuir-Hinshelwood kinetics. Appl. Surf. Sci. 2014, 320, 400-413. [CrossRef]

36. Petek, A.; Krajnc, M. The enthalpy and entropy of activation for ethyl acetate saponification. Int. J. Chem. Kinet. 2012, 44, 692-698. [CrossRef]

37. Consorti, C.S.; Flores, F.R.; Dupont, J. Kinetics and mechanistic aspects of the Heck reaction promoted by a CN-palladacycle. J. Am. Chem. Soc. 2005, 127, 12054-12065. [CrossRef]

38. Corma, S.W.A.; Llopis, F.; Monton, J.B. On the Compensation Effect in Acid-Base Catalyzed-Reactions on Zeolites-Reply. J. Catal. 1994, 148, 415-416. [CrossRef]

39. Bond, G.C.; Keane, M.A.; Kral, H.; Lercher, J.A. Compensation Phenomena in Heterogeneous Catalysis: General Principles and a Possible Explanation. Catal. Rev. Sci. Eng. 2000, 42, 323-383. [CrossRef]

40. Bond, G.C. Kinetics of alkane reactions on metal catalysts: Activation energies and the compensation effect. Catal. Today 1999, 49, 41-48. [CrossRef]

41. Rooney, J.J. The extended Eyring kinetic equation and the compensation effect in catalysis. J. Mol. Catal. A Chem. 1998, 129, 131-134. [CrossRef]

42. Kohantorabi, M.; Gholami, M.R. Kinetic Analysis of the Reduction of 4-Nitrophenol Catalyzed by $\mathrm{CeO}_{2}$ Nanorods-Supported CuNi Nanoparticles. Ind. Eng. Chem. Res. 2017, 56, 1159-1167. [CrossRef]

43. Chen, L.; Hu, J.; Qi, Z.; Fang, Y.; Richards, R. Gold nanoparticles intercalated into the walls of mesoporous silica as a versatile redox catalyst. Ind. Eng. Chem. Res. 2011, 50, 13642-13649. [CrossRef]

44. Vannice, M.A. Catalytic Reactions; Springer: New York, NY, USA, 2005.

45. Bielejewska, A.; Bylina, A.; Duszczyk, K.; Fiałkowski, M.; Hołyst, R. Evaluation of Ligand-Selector Interaction from Effective Diffusion Coefficient. Anal. Chem. 2010, 82, 5463-5469. [CrossRef]

46. Johnson, J.A.; Makis, J.J.; Marvin, K.A.; Rodenbusch, S.E.; Stevenson, K.J. Size-dependent hydrogenation of p-nitrophenol with $\mathrm{Pd}$ nanoparticles synthesized with poly(amido)amine dendrimer templates. J. Phys. Chem. C 2013, 117, 22644-22651. [CrossRef]

47. Zhao, P.; Feng, X.; Huang, D.; Yang, G.; Astruc, D. Basic concepts and recent advances in nitrophenol reduction by gold- and other transition metal nanoparticles. Coord. Chem. Rev. 2015, 287, 114-136. [CrossRef] 